\title{
Impact of C24:0 on actin-microtubule interaction in human neuronal SK-N-BE cells: evaluation by FRET confocal spectral imaging microscopy after dual staining with rhodamine-phalloidin and tubulin tracker green
}

\author{
Amira Zarrouk, PhD ${ }^{\mathrm{a}, \mathrm{b}}$ \\ Thomas Nury, MSc ${ }^{b}$ \\ Aurélien Dauphin, $\mathrm{PhD}^{\mathrm{c}}$ \\ Perrine Frère, $\mathrm{MSc}^{\mathrm{c}}$ \\ Jean-Marc Riedinger, PharmD ${ }^{d}$ \\ Claude-Marie Bachelet, $\mathrm{PhD}^{\mathrm{c}}$ \\ Frédérique Frouin, $\mathrm{PhD}^{\mathrm{e}}$ \\ Thibault Moreau, MD, PhD \\ Mohamed Hammami, PhD \\ Edmond Kahn, PhD \\ Gérard Lizard, PhD $^{\mathrm{b}}$
}

\begin{abstract}
a Université de Bourgogne, Equipe 'Biochimie du peroxysome, inflammation et métabolisme lipidique' EA7270 / INSERM, Faculté des Sciences Gabriel, Dijon, France

b Université de Monastir, Faculté de Médecine, LR12ES05, Lab-NAFS 'Nutrition - Functional Food \& Vascular Health', Monastir, Tunisia

c Plateforme d'Imagerie Cellulaire de la Pitié

Salpêtrière, UPMC, Paris, France

d Centre de Lutte Contre le Cancer GF Leclerc,

Laboratoire de Biologie Médicale, Dijon, France

e INSERM U678 / UMR - S UPMC, IFR 14, Faculté

de Médecine Pierre et Marie Curie - CHU Pitié

Salpétrière, Paris, France

${ }^{\dagger}$ Service de Neurologie, CHU de Dijon, Dijon, France
\end{abstract}

Correspondence to: Gérard Lizard

E-mail: gerard.lizard@u-bourgogne.fr

Summary

Disorganization of the cytoskeleton of neurons has major consequences on the transport of neurotransmitters via the microtubule network. The interaction of cytoskeleton proteins (actin and tubulin) was studied in neuronal SK-N-BE cells treated with tetracosanoic acid (C24:0), which is cytotoxic and increased in Alzheimer's disease patients. When SK-N-BE cells were treated with C24:0, mitochondrial dysfunctions and a non-apoptotic mode of cell death were observed.

Fluorescence microscopy revealed shrunken cells with perinuclear condensation of actin and tubulin.
After staining with rhodamine-phalloidin and with an antibody raised against $\alpha-/ \beta$-tubulin, modifications of $F$-actin and $\alpha$-/ $\beta$-tubulin levels were detected by flow cytometry. Lower levels of a-tubulin were found by Western blotting. In C24:0-treated cells, spectral analysis and fluorescence recovery after photobleaching (FRAP) measured by confocal microscopy proved the existence of fluorescence resonance energy transfer (FRET) when actin and tubulin were stained with tubulin tracker and rhodamine-phalloidin demonstrating actin and tubulin co-localization/interaction. In control cells, no FRET was observed.

Our data demonstrate quantitative changes in actin and tubulin, and modified interactions between actin and tubulin in SK-N-BE cells treated with C24:0. They also show that FRET confocal imaging microscopy is an interesting method for specifying the impact of cytotoxic compounds on cytoskeleton proteins.

KEY WORDS: actin, C24:0, FRET confocal spectral imaging microscopy, microtubule, rhodamine-phalloidin, tubulin tracker.

Introduction

Alzheimer's disease (AD; OMIM \# 104300) is the most common cause of dementia among neurodegenerative diseases in the elderly population (Ferri et al., 2005; Qiu et al., 2009). It is currently well recognized that the initiating event in $A D$ is related to excessive production of $\beta$-amyloid $(A \beta)$ peptides which are found in senile plaques in the AD brain (Russo et al., 2002; Jack et al., 2010, 2013). In the presence of amyloidogenic $A \beta$ peptides, a cascade of toxic events is activated. These include hyperphosphorylation of tau, a neuronal protein involved in microtubule stabilization that also contributes to microtubule dynamics and axonal transport (Cavallucci et al., 2012; Lee and Leugers, 2012). The pathogenic hyperphosphorylated form of tau favors disorganization of microtubules (made up of $\alpha$ - and $\beta$-tubulin subunits) (lqbal et al., 2010). In AD, microtubules and actin microfilaments, which are major components of the cytoskeleton of neurons and contribute to organelle trafficking as well as to the transport of neurotransmitters (Schrader et al., 2003; von Braun and Schleiff, 2007), are frequently altered (Bamburg and Bloom, 2009).

Peroxisomal function declines with age (Titorenko and Terlecky, 2011), and this can affect lipid and oxidative 
stress homoeostasis (Schrader and Fahimi, 2008; Del Rio, 2011); it is suggested that peroxisomes may play a critical part in regulating cellular aging and in the development of neurodegenerative diseases, including AD (Antonenkov et al., 2010). In agreement with this hypothesis, some lipid modifications resulting from peroxisomal dysfunctions are observed in the brains of AD patients (Kou et al., 2011): reduced levels of docosahexaenoic acid (DHA; C22:6 n-3) and plasmalogens, and increased levels of C22:0 and very long chain fatty acids (VLCFAs: C24:0 and C26:0) (Lizard et al., 2012). Increased levels of VLCFAs have also been found in the plasma and red blood cells of patients with $A D$ (Zarrouk, 2013). Notably, in glial and neuronal cells (Hein et al., 2008; Baarine et al., 2012; Zarrouk et al., 2012), it was previously reported that tetracosanoic acid (C24:0) (used at concentrations in the 5-20 $\mu \mathrm{M}$ range) is capable of triggering mitochondrial dysfunctions and oxidative stress associated with a non-apoptotic mode of cell death. These are regarded as important events leading to the development of AD (Kahn et al., 2011; Silva et al., 2012; von Bernhardi et al., 2012). As various fatty acids are able to favor significant disorganization of the cytoskeleton (de Kock et al., 1994; de Almeida et al., 2006; Borradaile et al., 2006; Kilner et al., 2012), it was deemed to be of interest to determine whether C24:0 might induce modifications of microtubules and actin, which, as mentioned above, are major components of the cytoskeleton. Briefly, the cytoskeleton is a network of fibers including microfilaments (polymers of G-actin), microtubules (polymers of $\alpha-$ and $\beta$-tubulins), and tissue-specific intermediate filaments. Different types of microfilaments are distinguished: type I and II (acidic and basic keratin proteins); type III (desmin, GFAP, peripherin, vimentin); type IV (a-internexin, neurofilaments, synemin, syncoilin); type $\mathrm{V}$ (lamins); type VI (nexin).

We focused on the activity of C24:0 for the following reasons: it is found at higher concentrations than C22:0 and C26:0 in the plasma and tissues of patients with peroxisomopathies (Kemp et al., 2011; Baarine et al., 2012), and it has also been detected at increased levels in the plasma and cortex of patients with $A D$ (Kou et al., 2011; Zarrouk, 2013; Zarrouk et al., 2015). Whereas this fatty acid is known to have pronounced side effects, contributing to cell death of various neural cells (Hein et al., 2008; Baarine et al., 2012; Zarrouk et al., 2012), its effects on the cytoskeleton are still unknown.

It was thus considered of interest to establish the precise impact of C24:0, at cytotoxic concentrations, on the organization of microtubules and actin in human neuronal SK-N-BE cells. To this end, it was necessary to develop appropriate methods, especially microscopic methods, which are among the most fascinating challenges in neuroscience (Silvestri et al., 2013). Indeed, whereas the expression of microtubules and actin can be studied by various conventional methods of biochemistry and flow cytometry, microscopic methods are required to determine the impact of various compounds on the cytoskeleton organization, especially the interaction between microtubules and actin microfilaments.
Since various fluorescent tools are available to stain microtubules and actin filaments, the interaction between these microfilaments inside cells can be determined by exploiting fluorescence resonance energy transfer (FRET), a distance-dependent interaction between two fluorescent molecules wherein excitation is transferred from a donor molecule to an acceptor molecule (Swift and Trinkle-Mulkahy, 2004). The FRET technique, currently a major technique for molecular interaction analysis (Renz, 2013; Sun et al., 2013), is based on spectral sequences of images obtained by confocal laser scanning microscopy (CLSM) and is a tool for identifying the possible co-localization of stained molecules. This approach makes it possible to characterize the possible action of various molecules, including lipids such as $\mathrm{C24:0}$, on the cytoskeleton organization, and it previously also enabled us to determine the effects of 7 ketocholesterol (7KC; an autoxidation product of cholesterol) and its interactions with cellular lipids stained with Nile Red during 7KC-induced apoptosis (Kahn et al., 2004; Vejux et al., 2005). Characterization of FRET can be performed by means of spectral signatures of fluorochromes, which show different spectral emissions according to whether excitation of the donor has an effect or has no effect on the acceptor. FRET can also be shown by fluorescence recovery after photobleaching (FRAP) of the acceptor in a selected region (Ishikawa-Ankerhold et al., 2012): in the presence of FRET, this photobleaching increases the intensity of the donor. In the case of spectral observations in which emissions of fluorochromes are collected via image sequences, factor analysis of medical image sequences (FAMIS) can be used to unmix sequences and provide factor curves and images of fluorescent structures inside cells when necessary (Kahn et al., 1999).

To provide precise information on the impact of C24:0 on the cytoskeleton of human neuronal SK-N-BE cells, different complementary microscopic, flow cytometric and biochemical methods were used. Our data demonstrate modified interactions between actin and tubulin in SK-N-BE cells treated with C24:0. They also provide evidence that the combined use of tubulin tracker (Oregon Green: donor), rhodamine-phalloidin (rhodamine: acceptor) and FRET confocal fluorescence microscopy associated with FAMIS (Kahn et al., 1997, 1999), which unmixes emissions of fluorochromes in stained samples and may provide images of co-localization, constitutes a powerful method for evaluating cytoskeleton structure and organization and the modification of interactions between microtubules and actin, which can occur under different treatment conditions.

\section{Materials and methods}

\section{Cells and cell treatments}

Human neuronal SK-N-BE cells were seeded at 400,000 cells per well in 12-well microplates containing $1 \mathrm{~mL}$ of culture medium (or at 800,000 cells per well in 6-well microplates containing $2 \mathrm{~mL}$ of culture 
medium), consisting of Dulbecco's modified Eagle medium with L-glutamine (DMEM) (Lonza, Levallois, France) supplemented with $10 \%(\mathrm{v} / \mathrm{v})$ heat-inactivated fetal bovine serum (FBS) (Pan Biotech, Aidenbach, Germany) and $1 \%$ antibiotics (100 $\mathrm{U} / \mathrm{mL}$ penicillin, 100 $\mathrm{mg} / \mathrm{mL}$ streptomycin) (Pan Biotech). Cells were incubated at $37^{\circ} \mathrm{C}$ in a humidified atmosphere containing $5 \% \mathrm{CO}_{2}$, and passaged twice a week. At each passage, SK-N-BE cells were trypsinized with a $0.05 \%$ trypsin-0.02\% EDTA solution (Pan Biotech).

Tetracosanoic acid (C24:0) (Sigma-Aldrich, St Louis, $\mathrm{MO}$, USA) was solubilized in a-cyclodextrin (SigmaAldrich) as previously described (Singh et al., 1983). The conditions of treatment with C24:0 were the following: after plating SK-N-BE cells for $24 \mathrm{~h}$, the cells were further treated for $48 \mathrm{~h}$ with various C24:0 concentrations $(0.1,1,5,10$, and/or $20 \mu \mathrm{M})$ in HAM's F-10 medium (Pan Biotech). The maximal final concentration of a-cyclodextrin (vehicle) in the culture medium, i.e. when C24:0 was used at $20 \mu \mathrm{M}$, was $1 \mathrm{mg} / \mathrm{mL}$.

\section{Analysis of cell morphology by phase contrast microscopy}

Cell morphology of SK-NB-E cells was observed after $48 \mathrm{~h}$ of culture in the absence or the presence of fatty acid (C24:0: 0.1, 1, 5, 10, and $20 \mu \mathrm{M})$ under an inverted-phase contrast microscope (Axiovert 40 CFL, Zeiss, Jena, Germany). The shape index evaluated by phase contrast microscopy was determined as previously described (Zarrouk et al., 2012). Digitized images were obtained with a camera (Axiocam ICm1, Zeiss).

Flow cytometric measurement of cells with depolarized mitochondria with $\mathrm{DiOC}_{6}(3)$

Variations of the mitochondrial transmembrane potential $\left(\Delta \Psi_{m}\right)$ were measured with 3,3'-dihexyloxacarbocyanine iodide $\left[\mathrm{DiOC}_{6}(3)\right]$ (Life Technologies, Fontenay-sous-Bois, France), which allows the percentage of cells with low $\Delta \Psi_{m}$ (cells with depolarized mitochondria) to be determined. To this end, adherent and non-adherent cells were pooled and stained with $\mathrm{DiOC}_{6}(3)$. With this fluorochrome, mitochondrial depolarization is indicated by a decrease in green fluorescence collected through a 520/10 nm bandpass filter. $\mathrm{DiOC}_{6}(3)$ was used at $40 \mathrm{nM}$ (Lemaire-Ewing et al., 2005). Flow cytometric analyses were performed on a Galaxy flow cytometer (Partec, Münster, Germany) equipped with a $488 \mathrm{~nm}$ blue laser. Ten thousand cells were acquired for each sample. Data were analyzed with Flomax software (Partec) or FlowJo software (Tree Star Inc., Ashland, OR, USA).

\section{Flow cytometric quantification of dead cells by staining with propidium iodide}

Adherent and non-adherent cells were pooled and stained with propidium iodide (PI; $5 \mu \mathrm{g} / \mathrm{mL}, 5 \mathrm{~min}$ ), which enters dead cells only (Yeh et al., 1981). The cells were then immediately analyzed with a Galaxy flow cytometer (Partec). Red fluorescence of PI was detected through a $625 \pm 20 \mathrm{~nm}$ bandpass filter, and fluorescent signals were measured on a logarithmic scale. For each sample, 10,000 cells were acquired and data were analyzed with Flomax (Partec) or FlowJo (Tree Star Inc.) software.

\section{Morphological characterization of cell death by nuclei staining with Hoechst 33342}

Nuclear morphology was characterized by fluorescence microscopy after staining with Hoechst 33342 $(1 \mu \mathrm{g} / \mathrm{mL})$ (Lizard et al., 1995). Cell deposits of about 40,000 cells were applied to glass slides by cytocentrifugation (5 min, 1,500 rpm) with a cytospin 2 (Shandon, Cheshire, UK), mounted in Dako fluorescent mounting medium (Dako, Copenhagen, Denmark), and stored in the dark at $4^{\circ} \mathrm{C}$ until observation. The morphology of the cell nuclei, which makes it possible to distinguish between viable, apoptotic and necrotic cells, was determined using an Axioskop fluorescent microscope (Zeiss). Viable cells are characterized by round and regular nuclei, apoptotic cells by condensed and/or fragmented nuclei, and necrotic cells by nuclei with irregular sizes and shapes (Lizard et al., 1995). For each sample, 300 cells were examined.

\section{Transmission electron microscopy}

Transmission electron microscopy (TEM) is a valuable tool for characterizing various cytotoxic effects (Lizard et al., 1995). It was used to visualize the possible ultrastructural modifications induced by $\mathrm{C} 24: 0$ in SK-N-BE cells, and was performed as previously described (Kahn et al., 2011).

Microscopic and flow cytometric evaluation of actin organization and polymerization after staining with rhodamine-phalloidin

The organization of the actin network was evaluated by fluorescence microscopy and flow cytometry after staining with rhodamine-phalloidin, which stains F-actin (Belloc et al., 1990). Microscopic observations were performed on SK-N-BE cells grown on glass coverslips. At the end of the treatment, the cells were washed with phosphate buffered saline (PBS), fixed with a $2 \%$ paraformaldehyde/PBS solution (10 min, room temperature), washed in PBS, and permeabilized with PBS $/ 0.05 \%$ saponin $/ 10 \%$ fetal calf serum (FCS) (30 $\mathrm{min}$, room temperature), and incubated (30 $\mathrm{min}$, room temperature, in the dark) in a $0.1 \mu \mathrm{M}$ rhodamine-phalloidin solution prepared in $\mathrm{PBS} / 0.05 \%$ saponin $10 \%$ FCS. Cell nuclei were counterstained with Hoechst $33342(1 \mu \mathrm{g} / \mathrm{mL})$. The slides were then mounted in fluorescent mounting medium (Dako), and stored in the dark at $4^{\circ} \mathrm{C}$ until microscopic examination. For conven- 
tional fluorescence microscopy, pictures were taken with an Axioskop fluorescent Zeiss microscope, and digitized images were obtained with an AxioCam digital camera (Zeiss).

Flow cytometric analyses were performed in order to quantify F-actin content. To this end, cells were trypsinized, washed and mixed in PBS and fixed in $2 \%$ paraformaldehyde/PBS solution (15 min, room temperature). After washing in PBS, cells were permeabilized with PBS $/ 0.05 \%$ saponin/10\% FCS (30 min, room temperature). Cells were then incubated in a $0.1 \mu \mathrm{M}$ rhodamine-phalloidin solution prepared in PBS/0.05\% saponin/10\% FCS (30 min, room temperature, in the dark). After washing in PBS, cells were resuspended in PBS and immediately analyzed by flow cytometry on a Galaxy flow cytometer (Partec). Fluorescence was collected through a $580 \pm 10 \mathrm{~nm}$ bandpass filter. For each sample, fluorescence was quantified on 10,000 cells, and data were analyzed with the Flomax software (Partec).

\section{Analysis of microtubule network organization by conventional fluorescence microscopy}

The organization of the microtubule network was evaluated by fluorescence microscopy with an antibody raised against $a$ - and $\beta$-tubulin subunits (Abcam, ab59680) or after staining with tubulin tracker $^{\mathrm{TM}}$ green (Oregon Green® 488 taxol, bis-acetate; Life Technologies), which provides green fluorescent staining of polymerized tubulin in the cells. For microscopic observations, SK-N-BE cells were grown on glass coverslips. For the immunofluorescence staining procedure, at the end of the treatment, cells were washed in PBS and fixed in absolute cold methanol (90\%/PBS solution) (3-5 $\mathrm{min}, 4^{\circ} \mathrm{C}$ ). After washing in PBS, cells were permeabilized with $\mathrm{PBS} / 0.05 \%$ saponin $/ 10 \%$ FCS (30 min, room temperature), and incubated with the primary antibody [rabbit polyclonal, recognizing a-/ $\beta$-tubulin (Abcam, ab59680)] diluted at $1 / 100$ in PBS/0.05\% saponin $10 \%$ FCS ( $1 \mathrm{~h}$, room temperature). Cells were then washed in PBS and incubated with an Alexa fluor 488 goat anti-rabbit antibody (Life Technologies) prepared at $1 / 40$ dilution in $\mathrm{PBS} / 0.05 \%$ saponin $/ 10 \%$ FCS (30 min, room temperature, in the dark). Cell nuclei were counterstained with Hoechst 33342 (1 $\mu \mathrm{g} / \mathrm{mL})$. The slides were then mounted in fluorescent mounting medium (Dako), and stored in the dark at $4^{\circ} \mathrm{C}$ until microscopic examination.

For the staining procedure with tubulin tracker green, at the end of the treatment, cells were washed with PBS, fixed with cold methanol 90\%/PBS solution (3-5 min, room temperature), and washed in PBS. Cells were then stained with tubulin tracker (200 nM, 5-10 min, room temperature). After washing in PBS, the nuclei were counterstained with Hoechst $33342(1 \mu \mathrm{g} / \mathrm{mL}, 5$ min, room temperature). The slides were then mounted in fluorescent mounting medium (Dako), and stored in the dark at $4^{\circ} \mathrm{C}$ until microscopic examination. For conventional fluorescence microscopy, pictures were taken with an Axioskop fluorescent Zeiss microscope, and digitized images were obtained with an AxioCam digital camera (Zeiss).

Actin and tubulin analysis by polyacrylamide gel electrophoresis and Western blotting

Cells washed in PBS were lysed in a RIPA buffer (10 mM Tris- $\mathrm{HCl}, \mathrm{pH} 7.2,150 \mathrm{mM} \mathrm{NaCl}, 0.5 \%$ Nonidet NP40, 0.5\% Na deoxycholate, 0.1\% SDS, 2 mM EDTA and $50 \mathrm{mM} \mathrm{NaF}$ ) in the presence of $1 / 25$ complete protease inhibitor cocktail tablets (Roche Diagnostics Corporation, Indianapolis, IN, USA) for $15 \mathrm{~min}$ on ice. Cell lysates were cleared by a 15-min centrifugation at $20,000 \mathrm{~g}$. The protein concentration was measured in the supernatant using the Bio-Rad protein assay kit (Bio-Rad, Marnes-la-Coquette, France). $30 \mu \mathrm{g}$ of proteins were diluted in loading buffer $(125 \mathrm{mM}$ Tris- $\mathrm{HCl}$, $\mathrm{pH} 6.8,10 \%$ b-mercaptoethanol, $4.6 \%$ SDS, $20 \%$ glycerol, and $0.003 \%$ bromophenol blue), separated on a polyacrylamide SDS-containing gel, and transferred onto a polyvinylidene difluoride membrane (BioRad). After blocking non-specific binding sites for $2 \mathrm{~h}$ with $3 \%$ non-fat milk and $1 \%$ bovine serum albumin in TBST (10 mM Tris- $\mathrm{HCl}, 150 \mathrm{mM} \mathrm{NaCl}, 0.1 \%$ Tween $20, \mathrm{pH} 8)$, the membrane was incubated overnight with the primary antibody diluted in TBST. The antibodies raised against a-tubulin (Santa-Cruz Biotechnology, Santa Cruz, CA, USA; ref sc5286) and $\beta$-actin (Sigma-Aldrich; ref A2228) were used at final concentrations of $1 / 300$ and $1 / 5,000$, respectively. The membrane was then washed twice with TBST and incubated for $45 \mathrm{~min}$ at room temperature with horseradish peroxidase-conjugated goat anti-mouse or antirabbit antibody (Santa-Cruz Biotechnology) diluted at $1 / 5,000$. The membrane was washed twice with TBST and revealed using an enhanced chemiluminescence detection kit (Amersham, Courtaboeuf, France) and autoradiography. The autoradiograms were quantified with ImageJ software (NIH, Besthesda, MD, USA).

\section{Dual staining of actin and tubulin with rhodamine- phalloidin and tubulin tracker}

To evaluate the interactions between actin and microtubules, which are two major components of the cytoskeleton, SK-N-BE cells were simultaneously stained with rhodamine-phalloidin and tubulin tracker. At the end of the incubation time, control (untreated cells), a-cyclodextrin (vehicle)-treated, and C24:0treated cells were washed in PBS, fixed in cold methanol ( $90 \%$, $3 \mathrm{~min}$, room temperature) and successively incubated with tubulin tracker (200 nM diluted in DMEM, 5-10 min, room temperature), rhodamine-phalloidin ( $1 \mu \mathrm{M}$ diluted in DMEM, 15-30 min, room temperature), and Hoechst $33342(1 \mu \mathrm{g} / \mathrm{ml}$ diluted in PBS, 5 min, room temperature). Between each step, cells were washed in PBS. The slides were then mounted in fluorescent mounting medium (Dako), and stored in the dark at $4^{\circ} \mathrm{C}$ until microscopic examination. Appropriate controls were performed: unstained cells, 
cells stained with tubulin tracker, rhodamine-phalloidin, Hoechst 33342, tubulin tracker + Hoechst 33342, and rhodamine-phalloidin + Hoechst 33342 , only.

\section{Fluorescence analysis by confocal laser scanning microscopy}

Confocal observations of untreated, a-cyclodextrintreated, and $\mathrm{C} 24: 0(5,10$ and $20 \mu \mathrm{M})$-treated SK-N-BE cells were carried out using a LEICA SP2 confocal laser scanning microscope (Leica, Wetzlar, Germany). Images at $0.2 \mu \mathrm{M}(\mathrm{x}, \mathrm{y})$ pixel sizes were obtained for each case in $512 \times 512$ matrices at CLSM magnification x 63 (objective: Plan-Apo, oil immersion, NA 1.4) with excitations at 488 and 543 $\mathrm{nm}$. Regular acquisitions resulted in bandpass filtered emissions (500-550 nm, 554-605 nm), and spectral sequences of 16 and 14 images were obtained through $10 \mathrm{~nm}$ bandpass filters in the 500-650 nm and $550-680 \mathrm{~nm}$ emission ranges at increments of 10 $\mathrm{nm}$. Interaction between stained actin and tubulin inside cells was determined by FRET, using these spectral sequences. Fluorescence associated with tubulin (Oregon Green, excitation: $488 \mathrm{~nm}$ ) has an action on the fluorescence of actin stained with rhodamine (excitation: $543 \mathrm{~nm}$ ) when these structures are co-localized as FRET is a distance-dependent interaction between two fluorescent molecules wherein excitation is transferred from a donor molecule to an acceptor molecule. A complementary set of experiments by fluorescence recovery after energy transfer (FRAP) was also performed to confirm the results obtained using the FRET technique, especially with regard to FRET efficiency. Therefore, as previously described (Bertolin et al., 2013), FRAP action was performed in a region of interest of the sample to verify whether photobleaching of the acceptor had the effect of increasing the fluorescence intensity of the donor. This occurs when FRET is possible.

\section{Image analysis}

Applying general factor analysis techniques, FAMIS was developed as a means of processing biomedical image sequences (Di Paola et al., 1982; Frouin et al., 1993). The procedure and the algorithms used on the cells by confocal microscopy have previously been described (Kahn et al., 1997, 1999). This development specifically required the use of constraints since FAMIS had to cope with mixtures of components characterized by different physical behaviors. Linearity and a component positivity basic hypothesis were investigated. FAMIS synthesizes image sequences into a reduced number of images called factor images and curves called factor curves (Kahn et al., 1997, 2000). The latter estimate individual behaviors in the sequence of images. Factor images correspond to spatial distribution components.

In performing FAMIS using Pixies software (Apteryx Inc., Gif sur Yvette, France; http://www.apteryx.fr/ pixies/index), pixels in matrices were combined accord- ing to $4 \times 4$ clusters of pixels. These clusters were all investigated in 512 x 512 matrices. Correspondence analysis (Harmann, 1960; Benzecri, 1973) was performed on the intensity evolution of each cluster. Then oblique analysis with positivity constraints was performed on the results of the correspondence analysis (Di Paola et al., 1982), necessitating positive factor curves and images. Factor images were recomputed in the original sample of images by oblique projection on the factor curves and the estimation was performed in the least-squares sense (Kahn et al., 1997, 1999, 2000). In the present context, the factor curves correspond to the emission spectra of the fluorochromes. Factor images provide images of stained fluorescent structures.

\section{Statistical analysis}

Statistical analyses were performed on at least three independent experiments using SigmaStat 2.03 software (Systat Software Inc., San Jose, CA, USA) with the Mann-Whitney test. Data were considered statistically different at a p-value of 0.05 or less.

\section{Results}

\section{Evaluation of the effects of C24:0 on cell viability}

When SK-N-BE cells were treated with C24:0 for $48 \mathrm{~h}$ in a range of concentrations from 0.1 to $20 \mu \mathrm{M}$, a dose-dependent increase of cells with depolarized mitochondria determined after staining with $\mathrm{DiOC}_{6}(3)$ was observed by flow cytometry: no effects were observed at $0.1 \mu \mathrm{M}$, slight effects at $5 \mu \mathrm{M}$, and marked effects at 10 and $20 \mu \mathrm{M}$ (Fig. $1 \mathrm{~A}$ ). The loss of transmembrane mitochondrial potential is associated with an increased permeability of the cytoplasmic membrane to $\mathrm{PI}$, which stains dead cells only: the most pronounced effects of C24:0 in terms of cell death induction were found at 10 and $20 \mu \mathrm{M}$ (Fig. 1 B). In addition, the induction of cell death triggered by C24:0 favored a loss of cell adhesion and an increase in cells with round nuclei was observed especially at 5, 10 and $20 \mu \mathrm{M}$ (Fig. $1 \mathrm{C}$ ). In agreement with previous observations, in the presence of C24:0 used at $20 \mu \mathrm{M}$, most of the cells were floating in the culture medium (Zarrouk et al., 2012). These functional and morphological changes were correlated with ultrastructural modifications inside the cells as shown by TEM. Whereas the distribution and the appearance (size and shape) of mitochondria were similar in the control (untreated cells) and a-cyclodextrin (vehicle)-treated cells (Fig. 2 A-B; D-E), major changes occurred in in the C24:0-treated cells (Fig. 2 C-F). Several elongated and round mitochondria could be observed in C24:0-treated cells (Fig. 2 F). No cells with condensed and/or fragmented nuclei, which are characteristic of apoptotic cells, were observed by TEM or by fluorescence microscopy after nuclei staining with Hoechst 33342 (Fig. 2 G-H-I). With the different flow cytomet- 


\section{A. Zarrouk et al.}

ric and microscopic methods used, C24:0-induced side effects were observed at a range of C24:0 concentrations: from 5 to $20 \mu \mathrm{M}$. As various cytotoxic fatty acids are able to produce disorganization of the cytoskeleton, we wondered whether a similar effect might occur in the presence of C24:0.

\section{Evaluation of the effect of C24:0 on actin and microtubule network organization: analysis by conventional fluorescence microscopy}

As SK-N-BE cells were severely damaged under treatment with C24:0 $(20 \mu \mathrm{M})$ (Fig. 1), we studied the effects of $\mathrm{C} 24: 0$ on actin and microtubule network organization at concentrations of 5 and $10 \mu \mathrm{M}$ only. Indeed, at these concentrations, a loss of transmembrane mitochondrial potential measured with $\mathrm{DiOC}_{6}(3)$ was observed as well as an increased membrane permeability to $\mathrm{Pl}$, whereas numerous cells were adherent (Fig. 1). Using conventional fluorescence microscopy and flow cytometry, actin was revealed after staining with rhodamine-phalloidin, and microtubules (made up of $\alpha$ - and $\beta$-tubulin subunits) were revealed with a rabbit polyclonal antibody raised against $\alpha$ - and $\beta$-tubulin subunits and a 488-Alexa fluor goat anti-rabbit antibody. Using conventional fluorescence microscopy, similar actin and microtubule
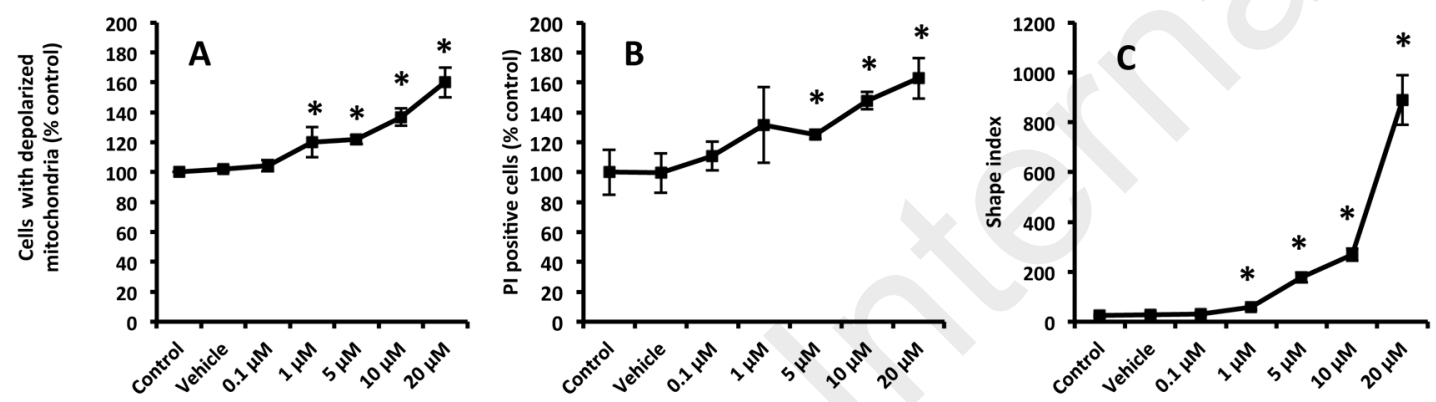

Figure 1 - Flow cytometric and microscopic analysis of C24:0-induced cell death.

Flow cytometry and phase contrast microscopy were used to characterize the effects of C24:0 $(0.1,1,5,10$ and $20 \mu \mathrm{M} ; 48 \mathrm{~h})$ on SK-N-BE cells. The ability of C24:0 to induce cell death was evaluated by various criteria: (A) measurement of the transmembrane mitochondrial potential $(\Delta \psi \mathrm{m})$ with $\mathrm{DiOC}_{6}(3)$ allowing quantification of cells with depolarized mitochondria. [In control and vehicle-treated cells, the percentage of cells with depolarized mitochondria $\left(\mathrm{DiOC}_{6}(3)\right.$-negative cells) was in the same range (5-10\%)]; (B) quantification of dead cells after staining with propidium iodide (PI). [In control and vehicletreated cells, the percentage of PI-positive cells was in the same range (5-10\%)]; (C) quantification of the presence of round cells determined according to the shape index (number of round cells/total number of cells $/ \mathrm{mm}^{2}$ ). Significance of the difference between control and treated cells is indicated by * (Mann-Whitney test; * $\mathrm{p}<0.05$ ). Significance of the difference between vehicle- and C24:0-treated cells is indicated by \# (Mann-Whitney test; \# $p<0.05$ ). No significant difference was observed between control and vehicle-treated cells.
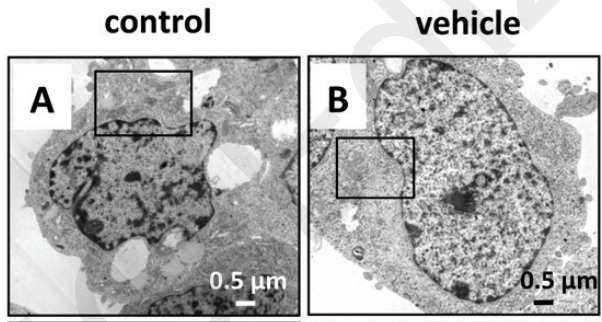

$\mathrm{C24:0}-10 \mu \mathrm{M}$
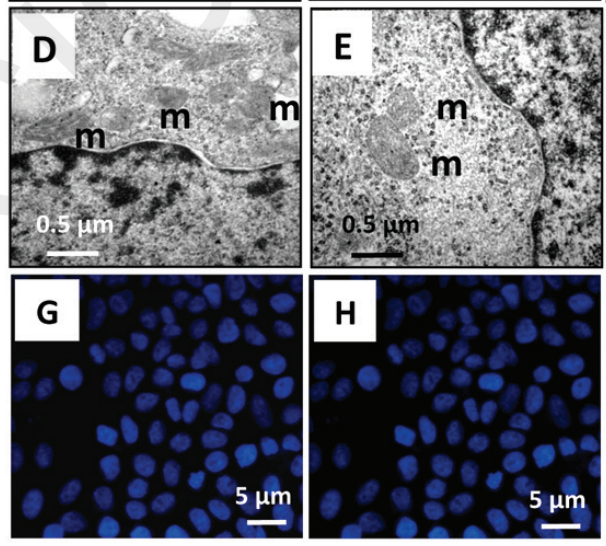
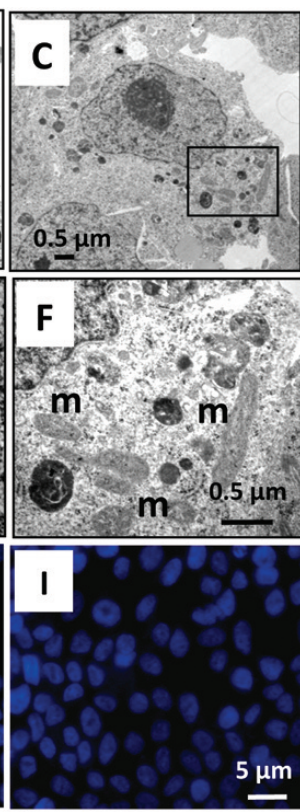

Figure 2 - Morphological characteristics of human neuronal cells (SK-N-BE) treated with C24:0; analysis by transmission electron microscopy and fluorescence microscopy.

Transmission electron microscopy (TEM) and conventional fluorescence microscopy of SK-N-BE cells cultured for $48 \mathrm{~h}$ in the absence (control cells) (A, D, G) or presence of acyclodextrin $(1 \mathrm{mg} / \mathrm{mL})$ (vehicle) (B, E, H), or C24:0 $(10 \mu \mathrm{M})$ $(C, F, I)$. The insets in figures $D, E$ and $F$ correspond to figures A, B, C, respectively. Some mitochondrial modifications were observed in C24:0-treated SK-N-BE cells (F), in comparison with control (D) and vehicle-treated cells $(E)$ : higher numbers of mitochondria, often larger in size, were found (m: mitochondria). TEM and fluorescence microscopy revealed no differences between control and vehicle-treated cells $(G, H, I)$; no signs of apoptosis (cells with perinuclear chromatin, with condensed and/or fragmented nuclei) were detected. 
network features were observed in control (untreated) cells and a-cyclodextrin (vehicle)-treated cells (Fig. 3 A-B, E-F). In C24:0 (5, $10 \mu \mathrm{M})$-treated cells, the size of the cells was reduced and the distribution of actin and microtubules was modified. Cells with condensed actin and microtubules around the nuclei (including round cells) could be detected (Fig. 3 C-D, G-H). All these observations support the fact that $\mathrm{C} 24: 0$ disor- ganizes the actin and microtubule network in SK-N-BE cells. By means of flow cytometry, modifications of levels of F-form actin [quantified by mean fluorescence intensity (MFI)] were detected in C24:0 (5, $10 \mu \mathrm{M})$ treated cells as compared to control cells and/or vehicle-treated cells characterized by similar MFI: a slight decrease was observed at $5 \mu \mathrm{M}$, whereas a marked increase was revealed at $10 \mu \mathrm{M}$ (Fig. 4A). We also

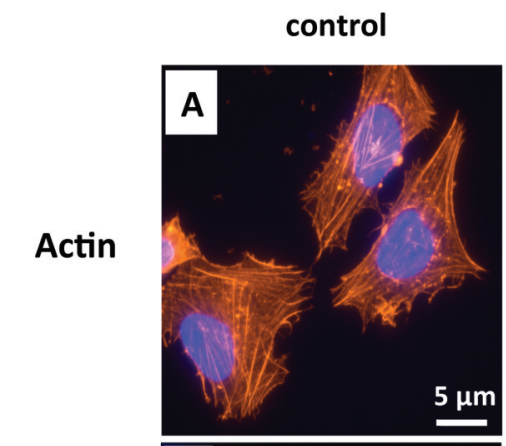

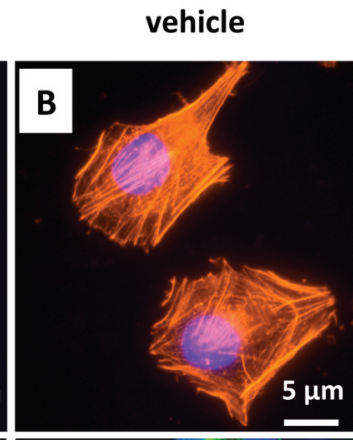

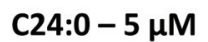
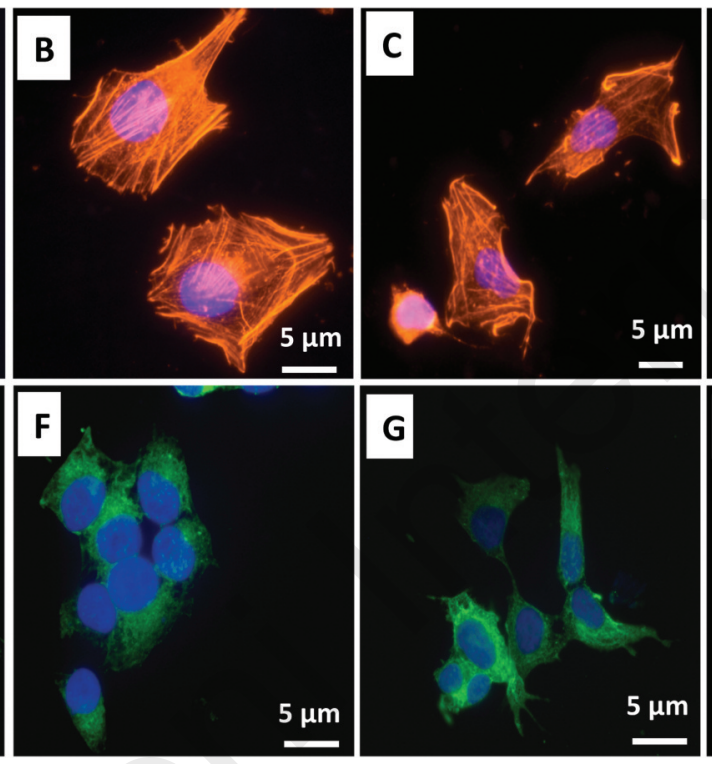

$\mathrm{C} 24: 0-10 \mu \mathrm{M}$
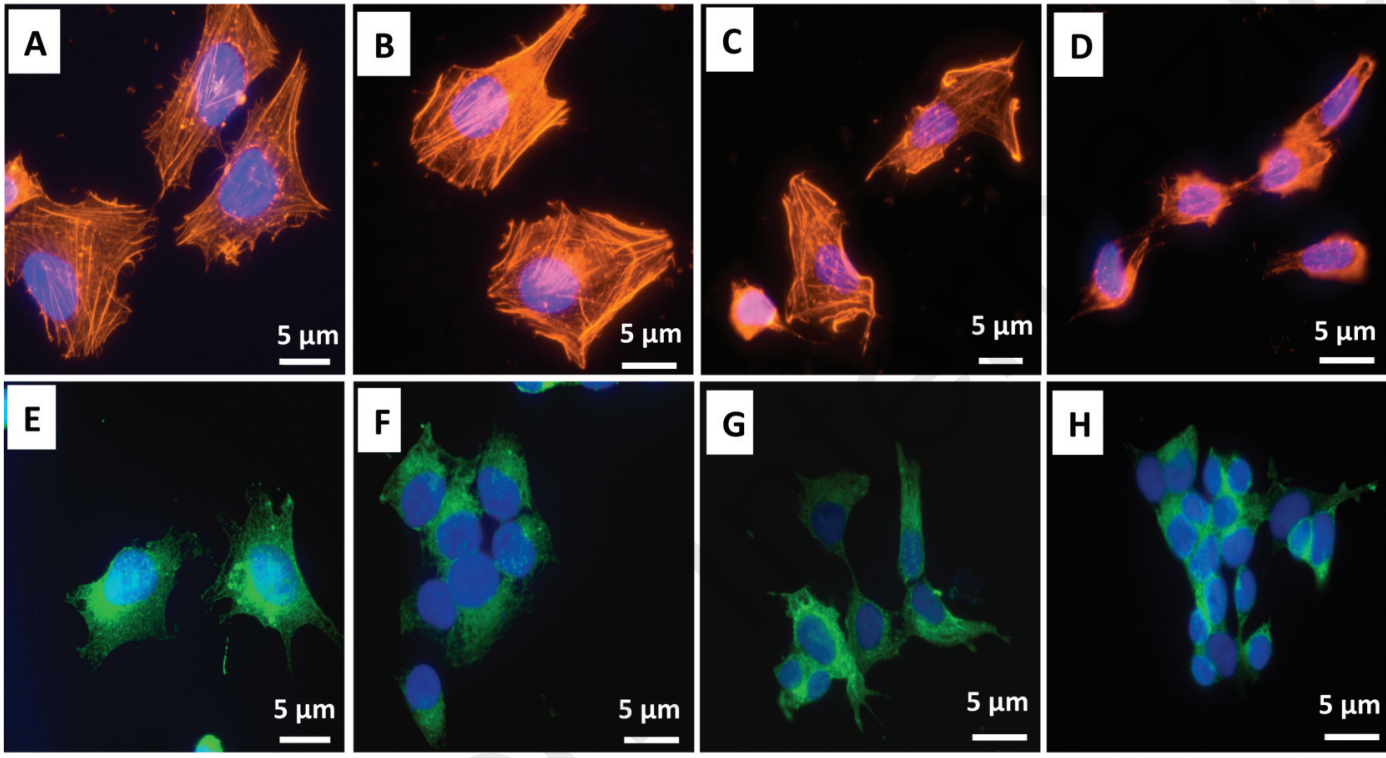

Figure 3 - Evaluation of actin and microtubule network organization by conventional fluorescence microscopy.

SK-N-BE cells were cultured for $48 \mathrm{~h}$ in the absence (control cells) or presence of vehicle (a-cyclodextrin: $1 \mathrm{mg} / \mathrm{mL}$ ), or C24:0 (5, 10 $\mu \mathrm{M})$. Actin-F was revealed with rhodamine-phalloidin staining, and microtubules were detected by indirect immunofluorescence with a rabbit polyclonal antibody raised against $\alpha$ - and $\beta$-tubulin subunits and a 488-Alexa fluor goat anti-rabbit antibody. The nuclei were counterstained with Hoechst 33342 ( $1 \mu \mathrm{g} / \mathrm{mL})$. No differences were revealed between control and vehicle-treated cells whereas perinuclear condensation of actin- $\mathrm{F}$ and $\mathrm{a}-/ \beta$-tubulin was observed in several C24:0-treated cells. The sizes of the cells and of the nuclei were also smaller under treatment with C24:0.

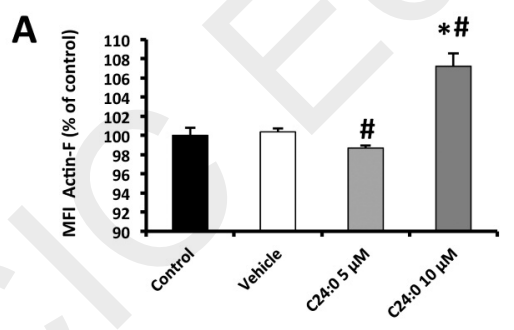

C

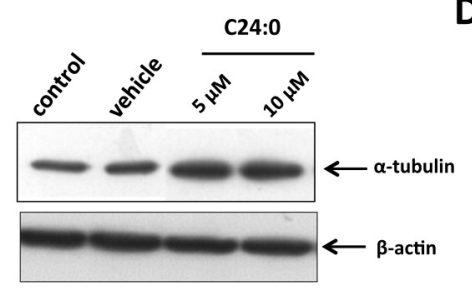

B

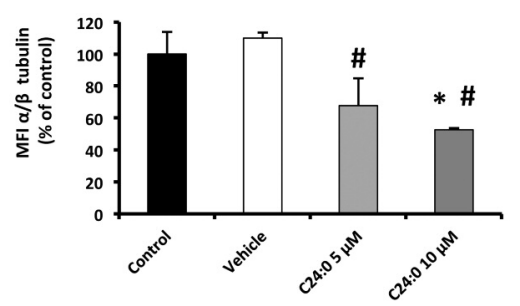

D

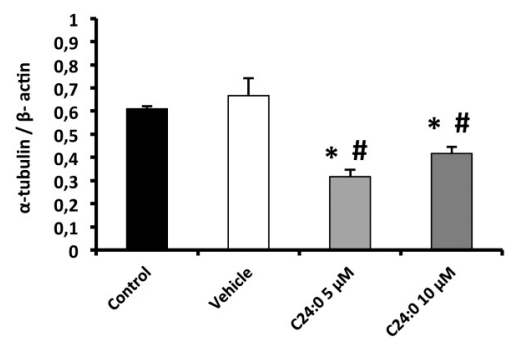

Figure 4 - Flow cytometric and biochemical quantification of actin and tubulin.

SK-N-BE cells were cultured for $48 \mathrm{~h}$ in the absence (control cells) or presence of acyclodextrin, $1 \mathrm{mg} / \mathrm{mL}$ (vehicle), or C24:0 $(5,10 \mu \mathrm{M})$. Flow cytometric quantification of actin and tubulin was performed after cell detachment by trypsinization. Actin-F was revealed with rhodamine-phalloidin $(A)$; tubulin was revealed with a rabbit polyclonal antibody raised against $\alpha$ - and $\beta$-tubulin subunits ( $\alpha-/ \beta$-tubulin) and a 488-Alexa fluor goat anti-rabbit antibody (B). In addition, the a-tubulin/ $\beta$-actin ratio was determined by Western blotting (C). Data shown are mean $\pm S D$ from three independent experiments. Significance of the difference between control and treated cells is indicated by * (Mann-Whitney test; * $\mathrm{p}<0.05$ ). Significance of the difference between vehicle and C24:0-treated cells is indicated by \# (Mann-Whitney test; \# $\mathrm{p}<0.05$ ). No significant difference was observed between control and vehicle-treated cells, therefore, data are expressed as $\%$ of control. 
took into consideration the a-tubulin/ $\beta$-tubulin ratio as well as the $\alpha$-tubulin/ $\beta$-actin ratio since these parameters can be used to evaluate modifications of microtubules and actin, which can favor alterations in microtubule structure/function and can contribute to modifying the interactions between microtubules and actin. By means of flow cytometry, significant decreases in a- and/or $\beta$-tubulin subunit content were found in C24:0 (5, $10 \mu \mathrm{M})$-treated cells, as compared to control cells and/or vehicle-treated cells characterized by similar MFI (Fig. 4B). Western blotting processing was used to study the ratio between a-tubulin and $\alpha$-actin in different culture conditions (Fig. $4 \mathrm{C}$ ); at 5 and 10 $\mu \mathrm{M}$, the a-tubulin/ $\beta$-actin ratio was reduced (Fig. $4 \mathrm{C}$ D). As a consequence, we wondered whether the interaction between actin and microtubules might be modified under treatment with C24:0 $(10 \mu \mathrm{M})$, which induced the most pronounced effects.

\section{Co-localization of actin and tubulin in C24:0-treat- ed SK-NB-E cells as evaluated by FRET confocal spectral imaging microscopy and FRAP}

As C24:0 $(10 \mu \mathrm{M})$ induced major topographic and quantitative modifications of the actin and microtubule organization of SK-N-BE cells, as revealed by conventional fluorescence microscopy (perinuclear accumulation of $\mathrm{F}$-actin and microtubules), flow cytometry (increased level of F-actin and $\alpha-/ \beta$-tubulin per cell), and Western blotting (reduced a-tubulin/ $\beta$-actin ratio), and simultaneously showed a marked effect on mito- chondrial transmembrane potential, permeability to $\mathrm{PI}$ (enhanced) and induction of round cells, this concentration was used for further confocal experiments. On untreated and C24:0 (10 $\mu \mathrm{M})$-treated SK-NB-E cells stained with tubulin tracker green (Oregon Green) only or with rhodamine-phalloidin (rhodamine) only, actinand microtubule-associated fluorescent signals were detected by CLSM (Fig. 5). The ability to co-localize microtubules revealed with Oregon Green (emission of a green fluorescence under $488 \mathrm{~nm}$ light) together with actin revealed with rhodamine (emission of an orange fluorescence under $543 \mathrm{~nm}$ light) is possible depending on the occurrence of FRET. When cells were not treated (control) or were treated with a-cyclodextrin (vehicle), microtubules and actin were properly and only excited at $488 \mathrm{~nm}$ and $543 \mathrm{~nm}$, respectively. When cells were treated with $\mathrm{C} 24: 0$, microtubules and actin were excited by means of the $488 \mathrm{~nm}$ light only demonstrating the occurrence of FRET, observed especially at the periphery of the cytoplasm (Fig. 6). In addition, the occurrence of FRET was supported by spectral image analysis performed with FAMIS: image analysis provided charts from spectral sequences and FAMIS processing provided factor curves and factor images in which peaks of emission were $525 \mathrm{~nm}$ and 565 nm, respectively (Fig. 7). Moreover, when FRAP was performed in a region of interest of C24:0-treated cells, the fluorescence of the donor increased when the acceptor was photobleached, thus supporting the occurrence of FRET and demonstrating actin and tubulin co-localization/interaction under treatment with this fatty acid (Fig. 8).

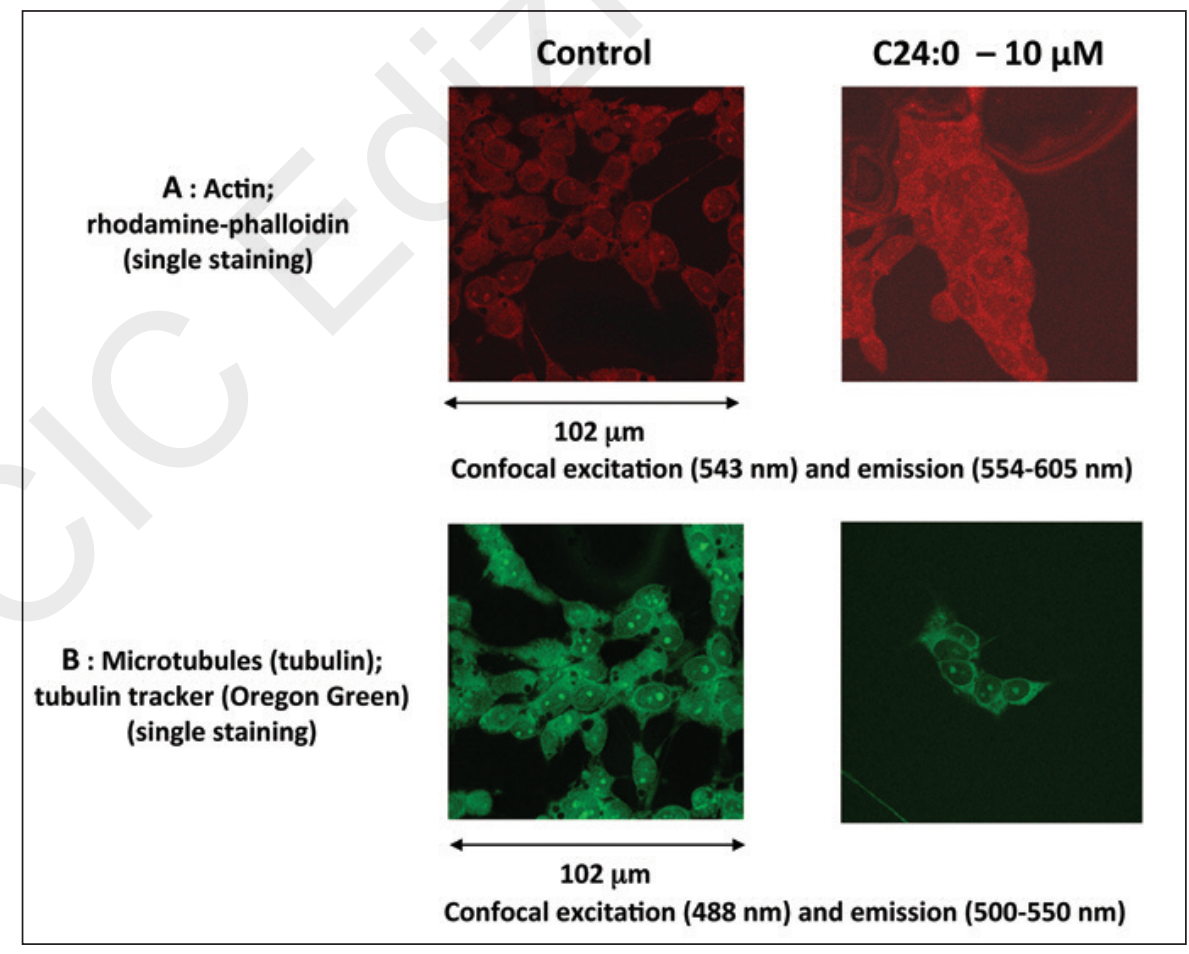

Figure 5 - Confocal images of control (untreated) and C24:0treated SK-N-BE cells: single staining.

Samples were stained with rhodamine-phalloidin (rhodamine: excitation $543 \mathrm{~nm} /$ emission 554$605 \mathrm{~nm}$ ) (A) or tubulin tracker (Oregon Green: excitation $488 \mathrm{~nm}$ / emission 554-605 nm) (B), which react with actin- $F$ or $\alpha-$ and $\beta$ tubulin subunits (major components of microtubules), respectively. 


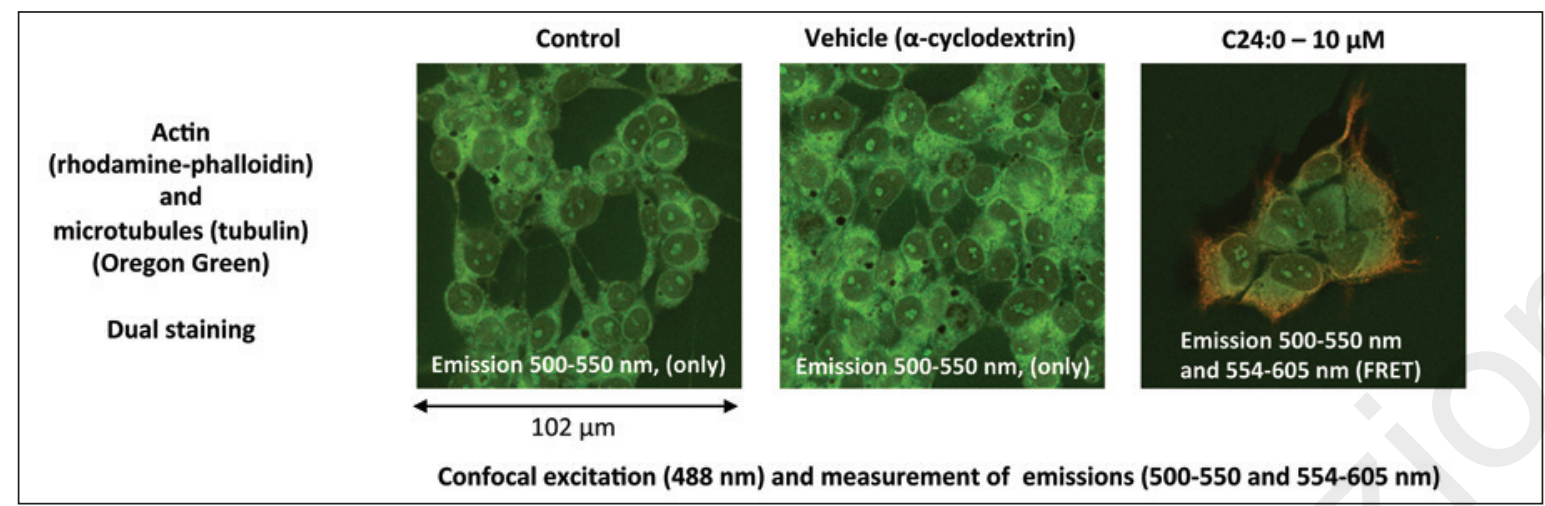

Figure 6 - Confocal images of control (untreated), a-cyclodextrin (vehicle)- and C24:0-treated SK-N-BE cells: dual staining. Samples were dual stained with tubulin tracker (Oregon Green: excitation $543 \mathrm{~nm} / \mathrm{emission}$ 554-605 nm) and rhodamine-phalloidin (rhodamine: excitation $488 \mathrm{~nm} / \mathrm{emission} 554-605 \mathrm{~nm}$ ) to reveal possible co-localizations of actin or microtubules (made up of a- and $\beta$-tubulin subunits) shown by the emission of an orange fluorescence under $488 \mathrm{~nm}$ light. Oregon Green (emission of a green fluorescence under $488 \mathrm{~nm}$ light) together with rhodamine (emission of an orange fluorescence under $543 \mathrm{~nm}$ light) makes it possible to have FRET in some localizations, Oregon Green being the donor and rhodamine being the acceptor. When cells were not treated (control) or were a-cyclodextrin (vehicle)-treated, microtubules and actin were properly excited at $488 \mathrm{~nm}$ and 543 $\mathrm{nm}$, respectively. No orange fluorescence $(554-605 \mathrm{~nm})$ was observed when the cells were excited at $488 \mathrm{~nm}$. However, when the cells were C24:0-treated, microtubules and actin were excited by means of the $488 \mathrm{~nm}$ light only: fluorescence emission was observed both at 500-550 $\mathrm{nm}$ and $554-605 \mathrm{~nm}$.

A

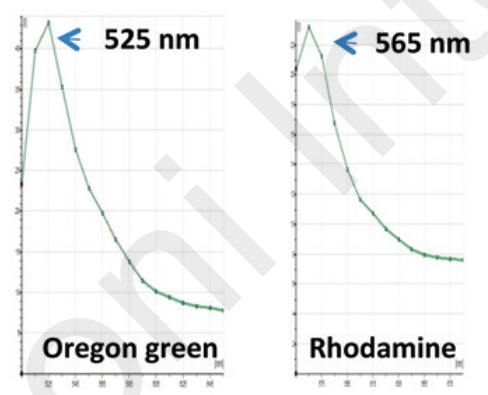

Confocal excitations (488 and $543 \mathrm{~nm}$ ), respectively Emission spectra : $505-655 \mathrm{~nm}$ and $555-685 \mathrm{~nm}$, respectively

Confocal excitation ( $488 \mathrm{~nm})$ : no FRET

Dual staining : rhodamine-phalloidin and tubulin tracker (Oregon Green)

\section{Only Oregon Green is detected}
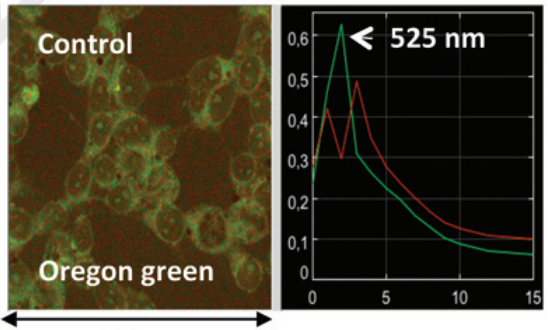

$102 \mu \mathrm{m}$

FAMIS : sequence of 16 emission images from 505 to $655 \mathrm{~nm}$

Confocal excitation (488 nm): FRET

Dual staining : rhodamine-phalloidin and tubulin tracker (Oregon Green)

Oregon Green and rhodamine are detected
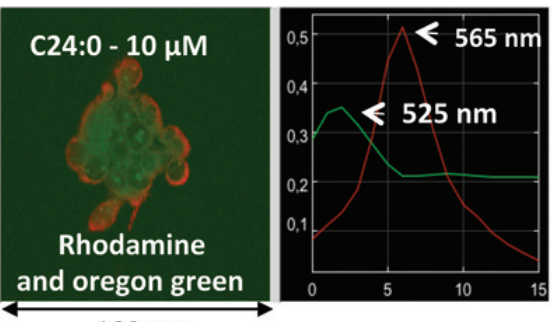

$102 \mu \mathrm{m}$

FAMIS : sequence of 16 emission images from 505 to $655 \mathrm{~nm}$

Figure 7 - FRET revealed by spectral image analysis (FAMIS).

Image analysis (FAMIS) provided charts (A) from spectral sequences obtained by means of $488 \mathrm{~nm}$ and $543 \mathrm{~nm}$ excitations, respectively. FAMIS processing provided factor curves and factor images from spectral sequences obtained by means of the $488 \mathrm{~nm}$ excitation only in superimposed images; (B) control (untreated SK-N-BE cells); (C) C24:0-treated SK-N-BE cells in which peaks of emission of green and orange factor images were $525 \mathrm{~nm}$ and 565 $\mathrm{nm}$, respectively. No FRET was observed in control cells (B) in which the first factor image was green; FRET was only observed in C24:0-treated cells (C) in which the first factor image was green and the second factor image was orange. 


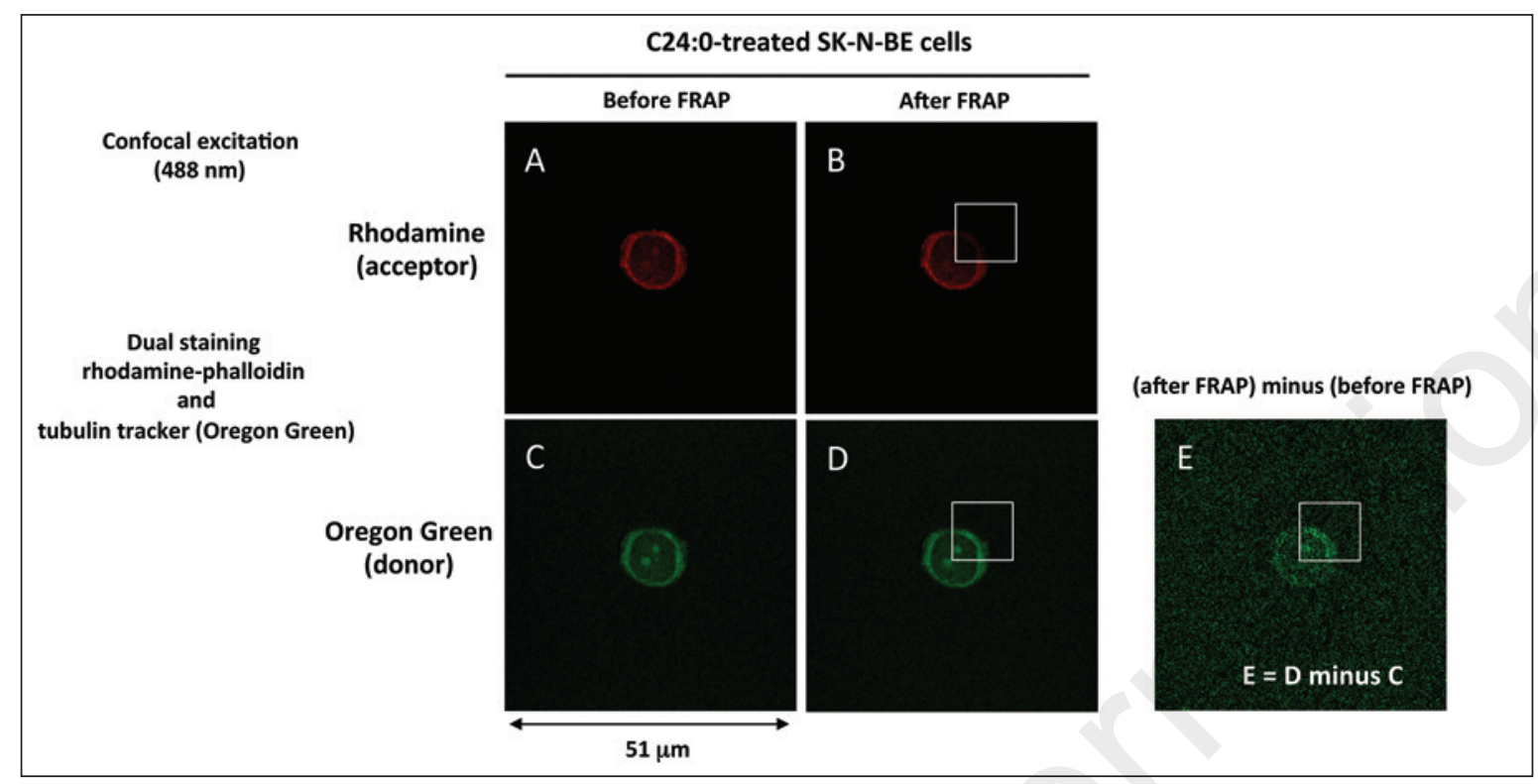

Figure 8 - Fluorescence resonance energy transfer (FRET) revealed by fluorescence recovery after photobleaching (FRAP).

When FRAP was performed under FRET conditions in a region of interest ( $B$ inside white square) in C24:0-treated cells, which were simultaneously stained with rhodamine-phalloidin (A) and tubulin tracker (Oregon Green) (C), the fluorescence of the donor (Oregon Green) increased (D) when the acceptor (rhodamine) (B) was photobleached. FRET efficiency is demonstrated in (E) via FRAP (Bertolin et al., 2013): after FRAP, the fluorescence of the donor inside the white square (D) was higher than before FRAP (C).

\section{Discussion}

Analysis of the cytoskeleton components is required in many research fields, which include cell differentiation, cell migration, cancer, neurology, pharmacology and toxicology. Indeed, some components of the cytoskeleton such as actin and microtubules are essential to maintain several cell functions. Thus, the activity of the mitochondrion, which is an essential organelle involved in energy production, glucose and lipid metabolism, redox homeostasis, and cell death control, depends on its interaction with actin and microtubules (Hollenbeck and Saxton, 2005). It is also reported that the activity of peroxisome, which is an essential organelle involved in the control of lipid metabolism, oxidation and non-cytokine inflammation (Ferdinandusse et al., 2002; Wanders and Waterham, 2006), depends in part on its interaction with microtubules (Thiemann et al., 2000; Schrader et al., 2003). As some modifications of actin and microtubules can occur in various normal or pathological conditions (aging, cancer, neurodegeneration) (Gourlay and Ayscough, 2005; Boldogh and Pon, 2007) or under the action of various molecules, methods able to highlight cytoskeleton modifications are of interest. In the present study, we characterized the effects of C24:0 on human neuronal SK-N-BE cells. As various cytotoxic effects associated with cell death have been observed in different cell types treated with C24:0 (Kahn et al., 2011; Baarine et al., 2012; Zarrouk et al., 2012; Hein et al., 2008), we wondered whether this fatty acid is able to induce cytoskeleton modifications. Using various flow cytometric, microscopic and biochemical methods, we demonstrated changes in actin and microtubules under treatment with $\mathrm{C} 24: 0$ used at 5 and $10 \mu \mathrm{M}$, both concentrations that are associated with the induction of cell death. Our data also established that it is possible to evaluate actin and tubulin interaction after staining with rhodamine-phalloidin and tubulin tracker which can produce FRET when they are co-localized. This phenomenom can be characterized by means of confocal spectral imaging microscopy. Moreover, available spectral imaging processing (FAMIS) provides visualization of this colocalization (Kahn et al., 1999).

Although accumulations of C24:0 are observed in various neurodegenerative diseases, including peroxisomopathies (Trompier et al., 2014) and, in particular, AD (Kou et al., 2011; Zarrouk, 2013; Zarrouk et al., 2015), the impact of this fatty acid on neural cells is still not well known. Indeed, only a few investigations on the side effects of VLCFAs are available (Singh and Pujol, 2010; Wanders et al., 2010). It has been suggested that the incorporation of VLCFAs by neuronal cells, and the presence of these fatty acids in their environment, can lead to dysfunctions and cell death. Indeed, in brain lesions of patients with X-linked adrenoleukodystrophy associated with tissue accumulation of C24:0, some dead cells, glial cells including oligodendrocytes and astrocytes especially, were detected (Feigenbaum et al., 2000; Eichler et al., 2008). Based on acute application of C24:0 to mixed hippocampal cell cultures containing oligodendrocytes, astrocytes and neurons from post-natal day 1-2 Wistar rat pups, which induces an increased $\mathrm{Ca}^{2+}$ level and a decrease in the $\Delta \Psi_{\mathrm{m}}$ in all the three cell types when this is measured with rhodamine 123 (Hein et al., 2008), the ability of C24:0 to trigger cell death in neu- 
ral cells is questionable. In the present study, performed using human neuronal SK-N-BE cells, the ability of C24:0 to favor cell death measured by enhanced permeability to $\mathrm{PI}$, which indicates cytoplasmic membrane damage and enters dead cells only (Yeh et al., 1981; Lizard et al., 1995), provides evidence that this fatty acid can also activate cell death in neuronal cells. Consequently, in a neurodegenerative disease such as in $A D$, increased accumulation of C24:0 in cortical lesions might contribute to neurodegeneration. Moreover, as mitochondria are known to play active roles in the mode of cell death triggered by biological, physical, and chemical agents (Kroemer et al., 2007), the influence of C24:0 on mitochondrial topography, morphology and functions was also studied. Under TEM, C24:0-treated, as compared to untreated or vehicle-treated cells, showed important topographical and morphological changes, especially clusters of mitochondria containing some elongated and round mitochondria in various areas of the cytoplasm, suggesting mitochondrial biogenesis. These mitochondrial elongations associated with increased mitochondrial mass (Zarrouk et al., 2012) can provide protection from organelle dysfunctions and degradation in order to maintain ATP levels (Gomes et al., 2011) and prevent cell death. Notably, as observed in C24:0-treated 158N murine oligodendrocytes (Kahn et al., 2011; Baarine et al., 2012), and according to morphological criteria (absence of cells with perinuclear chromatin, condensed and/or fragmented nuclei) (Lizard et al., 1995), C24:0 inducement of SK-N-BE cell death is a nonapoptotic mode of cell death associated with marked mitochondrial modifications (Zarrouk et al., 2012). As the ability of $\mathrm{C} 24: 0$ to induce a non-apoptotic mode of cell death, evoking necrosis and/or necroptosis (Linkermann and Green, 2014), has also been described on $158 \mathrm{~N}$ murine oligodendrocytes (Kahn et al., 2011), our data support that the mode of cell death induced by C24:0 does not depend on the cell type considered. Moreover, the absence of caspase-3 activation observed in C24:0-treated SK-N-BE cells supports the induction of a non-apoptotic mode of cell death (our data, not shown). In addition, as C24:0 promotes the conversion of microtubule-associated protein light chain 3 (LC3) to LC3-I and LC3-II, which is clearly correlated with the number of autophagosomes (Mizushima and Yoshimori, 2007), it is supposed that C24:0-induced cell death also triggers an autophagic process (our data, not shown). It remains to be determined whether this autophagic process arises to counteract or to contribute to cell death (Kaminskyy and Zhivotovsky, 2012; Ryter et al., 2014).

Since it is reported that changes in the dynamics of microtubules can potentially exert profound effects on the homeostasis of mitochondria since the distribution and morphology of mitochondria and other organelles in mammalian cells are largely dependent upon the integrity of microtubules (Tanaka et al., 1998; Karbowski et al., 2001), it is important to determine the effects of $\mathrm{C} 24: 0$ on microtubules. Moreover, as reactive oxygen species (ROS) are produced under treatment with C24:0 (Zarrouk et al., 2012), and can react with cellular macromolecules, their overproduction can induce modifications at various cellular levels, especially at the cytoskeleton level, and contribute to the formation of round cells and to the loss of cell adhesion (Zahm et al., 2003). Indeed, ROS can act through several pathways on various components of the cytoskeleton such as actin fibers (Lum and Roebuck, 2001). Therefore, overproduction of ROS can be suspected to play a part in the alteration of actin and microtubules. Thus, as actin and microtubule disorganization is observed in AD (lqbal et al., 2010; Satoh et al., 2013), it is worth highlighting the impact of C24:0 on the actin and microtubule network. Under treatment with $\mathrm{C} 24: 0$, the lower a-tubulin subunit/ $\beta$-tubulin subunit ratio may have important consequences on microtubule properties, such as stability and structure, microtubule-based functions including cell division and intracellular trafficking, as well as on interactions with other proteins of the cytoskeleton (Hammond et al., 2008; de Forges et al., 2012). In addition, as important topographic and quantitative modifications of actin and microtubule organization of SK-N-BE cells have been revealed by conventional fluorescence microscopy, flow cytometry and Western blotting, it was deemed to be of interest to clarify the precise consequences of treatment with this fatty acid on the interaction between actin and microtubules. To this end, two dyes were used simultaneously, one reacting with actin (rhodamine-phalloidin: a bicyclic peptide isolated from the deadly Amanita phalloides mushroom conjugated to the red-orange fluorescent dye, tetramethylrhodamine) and the other with microtubules [tubulin tracker (Oregon Green ${ }^{\circledR} 488$ taxol, bis-acetate), providing a green-fluorescent staining of polymerized tubules]. In the C24:0-treated cells, spectral analysis through confocal microscopy proved the existence of FRET when actin and tubulin are stained with tubulin tracker (Oregon Green: donor) and rhodamine-phalloidin (rhodamine: acceptor) whereas no FRET was observed in untreated cells or a-cyclodextrin (vehicle)-treated cells. Therefore, the present investigation, with the simultaneous use of Oregon Green, rhodamine, CLSM and spectral imaging methods (FAMIS) constitutes a new method that allows the co-localization of actin and tubulin in C24:0-treated cells to be determined on the basis of FRET revealed by spectral analysis of fluorescence emissions. There exist various other FRET detection methods, such as FRAP, based on acceptor or donor photobleaching (Swift and Trinkle-Mulkahy, 2004). Here, we used the acceptor photobleaching method in which bleaching of the acceptor molecule results in a brightening of the donor fluorescence (Bertolin et al., 2013). As such, the use of FRAP in complementary experiments on the acceptor confirmed the existence of FRET, showing an increase in the intensity of donor fluorescence in C24:0-treated cells. This technical approach, which is easy to perform, may find a wide range of applications in several biological fields in which it is necessary to clarify the interactions between actin and microtubules in various normal and pathological processes or under the action of various compounds. 
In pharmacology and toxicology, the possibility of developing automated micro-methods based on the simultaneous use of rhodamine-phalloidin, tubulin tracker green and FRET could be of interest for identifying biological, chemical and physical agents capable of modifying actin and microtubule interactions. From a physiopathological point of view, our data also suggest that $\mathrm{C} 24: 0$ could contribute to the formation of the characteristic lesions of AD: neurofibrillary tangles (intracellular disorganized microtubules associated with tau protein under its hyperphosphorylated form) (Medeiros et al., 2011), neuritic plaques (extracellular deposits consisting of $\beta$-amyloid protein mixed with branches of dying nerve cells), and Hirano bodies (intracellular eosinophilic aggregates composed of actin and actin-associated proteins) (Hirano, 1994; Maselli et al., 2002), which are sites of accumulation of abnormal fibrillar material (Crowther, 1990).

Overall, the present study, based on the use of various microscopy and flow cytometry methods, demonstrated that C24:0-induced cell death is associated with important modifications of actin and microtubules, which are major components of the cytoskeleton. This circumstance may have some consequences on mitochondrial and peroxisome activity, which depends on the organization of actin and microtubules (Tanaka et al., 1998; Karbowski et al., 2001; Thiemann et al., 2000), respectively, and supports the hypothesis that C24:0 found at increased levels in the cortex of patients with AD (Kou et al., 2011) might contribute to the development of this disease. In addition, we established that the combined use of tubulin tracker, rhodamine-phalloidin and FRET confocal fluorescence microscopy associated with FAMIS constitutes a new and useful method for evaluating the interactions between microtubules and actin.

\section{Acknowledgments}

This work was supported by grants from the INSERM, the Université de Bourgogne (Dijon, France), the Université de Monastir (Monastir, Tunisia), the University Hospital of Dijon (France), the Conseil Régional de Bourgogne (Dijon, France), and ABASIM (Dijon, France).

\section{References}

Antonenkov VD, Grunau S, Ohlmeier S, et al (2010). Peroxisomes are oxidative organelles. Antioxid Redox Signal 13:525-537.

Baarine M, Ragot K, Athias A, et al (2012). Incidence of Abcd1 level on the induction of cell death and organelle dysfunctions triggered by very long chain fatty acids and TNF- $a$ on oligodendrocytes and astrocytes. Neurotoxicology 33:212228.

Bamburg JR, Bloom GS (2009). Cytoskeletal pathologies of Alzheimer disease. Cell Motil Cytoskeleton 66:635-649.

Belloc JF, Vincendeau P, Freyburger G, et al (1990). Flow cytometric study of the activation of polymorphonuclear cells. J Leukoc Biol 48:353-358.
Benzecri JP (1973). L'analyse des données, Tome 2: L'analyse des correspondances. Paris, Dunod.

Bertolin G, Ferrando-Miguel R, Jacoupy M, et al (2013). The TOMM machinery is a molecular switch in PINK1 and PARK2/PARKIN-dependent mitochondrial clearance. Autophagy 9:1801-1817.

Boldogh IR, Pon LA (2007). Mitochondria on the move. Trends Cell Biol 17: 502-510.

Borradaile NM, Buhman KK, Listenberger LL, et al (2006). A critical role for eukaryotic elongation factor $1 \mathrm{~A}-1$ in lipotoxic cell death. Mol Biol Cell 17:770-778.

Cavallucci V, D'Amelio M, Cecconi $F$ (2012). A $\beta$ toxicity in Alzheimer's disease. Mol Neurobiol 45:366-378.

Crowther RA (1990). Structural aspects of pathology in Alzheimer's disease. Biochim Biophys Acta 1096:1-9.

de Almeida LM, Funchal C, Gottfried C, et al (2006). Propionic acid induces cytoskeletal alterations in cultured astrocytes from rat cerebral cortex. Metab Brain Dis 21:51-62.

de Forges H, Bouissou A, Perez F (2012). Interplay between microtubule dynamics and intracellular organization. Int $\mathrm{J}$ Biochem Cell Biol 44:266-274.

de Kock M, Lottering ML, Seegers JC (1994). Differential cytotoxic effects of gamma-linolenic acid on MG-63 and HeLa cells. Prostaglandins Leukot Essent Fatty Acid 51:109120.

Del Río LA (2011). Peroxisomes as a cellular source of reactive nitrogen species signal molecules. Arch Biochem Biophys 506:1-11.

Di Paola R, Bazin JP, Aubry F, et al (1982). Handling of dynamic sequences in nuclear medicine. IEEE Transactions on Nuclear Science 29:1310-1321.

Eichler FS, Ren JQ, Cossoy M, et al (2008). Is microglial apoptosis an early pathogenic change in cerebral X-linked adrenoleukodystrophy? Ann Neurol 63:729-742.

Feigenbaum V, Gélot A, Casanova P, et al (2000). Apoptosis in the central nervous system of cerebral adrenoleukodystrophy patients. Neurobiol Dis 7:600-612.

Ferdinandusse S, Meissner T, Wanders RJ, et al (2002). Identification of the peroxisomal beta-oxidation enzymes involved in the degradation of leukotrienes. Biochem Biophys Res Commun 293:269-273.

Ferri CP, Prince M, Brayne C, et al (2005). Alzheimer's Disease International. Global prevalence of dementia: a Delphi consensus study. Lancet 366:2112-2117.

Frouin F, Cinotti L, Benali H, et al (1993). Extraction of functional volumes from medical dynamic volumetric datasets. Comput Med Imaging Graph 17:397-404.

Gomes LC, Di Benedetto G, Scorrano L (2011). During autophagy mitochondria elongate, are spared from degradation and sustain cell viability. Nat Cell Biol 13:589-598.

Gourlay CW, Ayscough KR (2005). The actin cytoskeleton in ageing and apoptosis. FEMS Yeast Res 5:1193-1198.

Hammond JW, Cai D, Verhey KJ (2008). Tubulin modifications and their cellular functions. Curr Opin Cell Biol 20:71-76.

Harman HH (1960). Modern Factor Analysis. Chicago, University of Chicago Press.

Hein S, Schönfeld P, Kahlert S, et al (2008). Toxic effects of Xlinked adrenoleukodystrophy-associated, very long chain fatty acids on glial cells and neurons from rat hippocampus in culture. Hum Mol Genet 17:1750-1761.

Hirano A (1994). Hirano bodies and related neuronal inclusions. Neuropathol Appl Neurobiol 20:3-11.

Hollenbeck PJ, Saxton WM (2005). The axonal transport of mitochondria. J Cell Sci 118:5411-5419.

Iqbal K, Liu F, Gong CX, et al (2010). Tau in Alzheimer disease and related tauopathies. Curr Alzheimer Res 7:656-664.

Ishikawa-Ankerhold HC, Ankerhold R, Drummen GP (2012). 
Advanced fluorescence microscopy techniques-FRAP, FLIP, FLAP, FRET and FLIM. Molecules 17:4047-4132.

Jack CR Jr, Knopman DS, Jagust WJ, et al (2013). Tracking pathophysiological processes in Alzheimer's disease: an updated hypothetical model of dynamic biomarkers. Lancet Neurol 12:207-216.

Jack CR Jr, Knopman DS, Jagust WJ, et al (2010). Hypothetical model of dynamic biomarkers of the Alzheimer's pathological cascade. Lancet Neurol 9:119-128.

Kahn E, Baarine M, Dauphin A, et al (2011). Impact of 7-ketocholesterol and very long chain fatty acids on oligodendrocyte lipid membrane organization: evaluation via LAURDAN and FAMIS spectral image analysis Cytometry A 79:293-305.

Kahn E, Vejux A, Dumas D, et al (2004). FRET multiphoton spectral imaging microscopy of 7-ketocholesterol and Nile Red in U937 monocytic cells loaded with 7-ketocholesterol. Anal Quant Cytol Histol 26:304-313.

Kahn E, Frouin F, Souchier C, et al (2000). Confocal multilaser focusing and single-laser characterization of ultraviolet excitable stains of cellular preparations. Cytometry 40:42-49.

Kahn E, Lizard G, Pélégrini M, et al (1999). Four-dimensional factor analysis of confocal image sequences (4D-FAMIS) to detect and characterize low numbers of human papillomavirus DNA by FISH in HeLa and SiHa cells. J Microsc 193:227-243.

Kahn E, Lizard G, Frouin F, et al (1997). Laser scanning confocal microscopy and factor analysis of biomedical image sequences (FAMIS) to detect and characterise HPV DNA sequences by FISH in HeLa cells. Cytometry 28:269-279.

Kaminskyy V, Zhivotovsky B (2012). Proteases in autophagy. Biochim Biophys Acta 1824:44-50.

Karbowski M, Spodnik JH, Teranishi M, et al (2001). Opposite effects of microtubule-stabilizing and microtubule-destabilizing drugs on biogenesis of mitochondria in mammalian cells. J Cell Sci 114(Pt 2):281-291.

Kemp S, Theodoulou FL, Wanders RJ (2011). Mammalian peroxisomal $A B C$ transporters: from endogenous substrates to pathology and clinical significance. $\mathrm{Br} \mathrm{J}$ Pharmacol 164:1753-1766.

Kilner J, Waby JS, Chowdry J, et al (2012). A proteomic analysis of differential cellular responses to the short-chain fatty acids butyrate, valerate and propionate in colon epithelial cancer cells. Mol Biosyst 8:1146-1156.

Kou J, Kovacs GG, Höftberger R, et al (2011). Peroxisomal alterations in Alzheimer's disease. Acta Neuropathol 122:271-283.

Kroemer G, Galluzzi L, Brenner C (2007). Mitochondrial membrane permeabilization in cell death. Physiol Rev 87:99163.

Lee G, Leugers CJ (2012). Tau and tauopathies. Prog Mol Biol Transl Sci 107:263-293.

Lemaire-Ewing S, Prunet C, Montange T, et al (2005). Comparison of the cytotoxic, pro-oxidant and pro-inflammatory characteristics of different oxysterols. Cell Biol Toxicol 21:97-114.

Linkermann A, Green DR (2014). Necroptosis. N Engl J Med 370:455-465.

Lizard G, Rouaud O, Demarquoy J, et al (2012). Potential roles of peroxisomes in Alzheimer's disease and in dementia of the Alzheimer's type. J Alzheimers Dis 29:241-254.

Lizard G, Fournel S, Genestier L, et al (1995). Kinetics of plasma membrane and mitochondrial alterations in cells undergoing apoptosis. Cytometry 21:275-283.

Lum H, Roebuck KA (2001). Oxidant stress and endothelial cell dysfunction. Am J Physiol Cell Physiol 280:C719-741.

Maselli AG, Davis R, Furukawa R, et al (2002). Formation of
Hirano bodies in Dictyostelium and mammalian cells induced by expression of a modified form of an actincrosslinking protein. J Cell Sci 115:1939-1949.

Medeiros R, Baglietto-Vargas D, LaFerla FM (2011). The role of tau in Alzheimer's disease and related disorders. CNS Neurosci Ther 17:514-524.

Mizushima N, Yoshimori T (2007). How to interpret LC3 immunoblotting. Autophagy 3:542-545.

Qiu C, Kivipelto M, von Strauss E (2009). Epidemiology of Alzheimer's disease: occurrence, determinants, and strategies toward intervention. Dialogues Clin Neurosci 11:111-128.

Renz M (2013). Fluorescence microscopy - a historical and technical perspective. Cytometry A 83:767-779.

Russo C, Venezia V, Salis S, et al (2002). Molecular aspects of neurodegeneration in Alzheimer's disease. Funct Neurol 17:65-70.

Ryter SW, Mizumura K, Choi AM (2014). The impact of autophagy on cell death modalities. Int $\mathrm{J}$ Cell Biol 2014:502676.

Satoh J, Tabunoki H, Ishida T, et al (2013). Ubiquilin-1 immunoreactivity is concentrated on Hirano bodies and dystrophic neurites in Alzheimer's disease brains. Neuropathol Appl Neurobiol 39:817-830.

Schrader M, Fahimi HD (2008). The peroxisome: still a mysterious organelle. Histochem Cell Biol 129:421-440.

Schrader M, Thiemann M, Fahimi HD (2003). Peroxisomal motility and interaction with microtubules. Microsc Res Tech 61:171-178.

Silva DF, Selfridge JE, Lu J, et al (2012). Mitochondrial abnormalities in Alzheimer's disease: possible targets for therapeutic intervention. Adv Pharmacol 64:83-126.

Silvestri L, Sacconi L, Pavone FS (2013). The connectomics challenge. Funct Neurol 28:167-173.

Singh I, Pujol A (2010). Pathomechanisms underlying Xadrenoleukodystrophy: a three-hit hypothesis. Brain Pathol 20:838-844.

Singh I, Kishimoto Y (1983). Effect of cyclodextrins on the solubilization of lignoceric acid, ceramide, and cerebroside, and on the enzymatic reactions involving these compounds. J Lipid Res 24:662-665.

Sun Y, Rombola C, Jyothikumar V, et al (2013). Forster resonance energy transfer microscopy and spectroscopy for localizing protein-protein interactions in living cells. Cytometry A 83:780-793.

Swift SR, Trinkle-Mulkahy L (2004). Basic principles of FRAP, FLIM and FRET. Proceedings of the Royal Microscopical Society 39:3-10.

Tanaka Y, Kanai Y, Okada Y, et al (1998). Targeted disruption of mouse conventional kinesin heavy chain, kif5B, results in abnormal perinuclear clustering of mitochondria. Cell 93:1147-1158.

Thiemann M, Schrader M, Völkl A, et al (2000). Interaction of peroxisomes with microtubules. In vitro studies using a novel peroxisome-microtubule binding assay. Eur $\mathrm{J}$ Biochem 267:6264-6275.

Titorenko VI, Terlecky SR (2011). Peroxisome metabolism and cellular aging. Traffic 12:252-259.

Trompier D, Vejux A, Zarrouk A, et al (2014). Brain peroxisomes. Biochimie 98:102-110.

Vejux A, Kahn E, Dumas D, et al (2005). 7-ketocholesterol favors lipid accumulation and colocalizes with Nile Red positive cytoplasmic structures formed during 7-ketocholesterol-induced apoptosis: analysis by flow cytometry, FRET biphoton spectral imaging microscopy, and subcellular fractionation. Cytometry A 64:87-100.

von Bernhardi R, Eugenín J (2012). Alzheimer's disease: 


\section{A. Zarrouk et al.}

redox dysregulation as a common denominator for diverse pathogenic mechanisms. Antioxid Redox Signal 16:974-1031.

Von Braun SS, Schleiff E (2007). Movement of endosymbiotic organelles. Curr Protein Pept Sci 8:426-438.

Wanders RJ, Ferdinandusse S, Brites P, et al (2010). Peroxisomes, lipid metabolism and lipotoxicity. Biochim Biophys Acta 1801:272-280.

Wanders RJ, Waterham HR (2006). Biochemistry of mammalian peroxisomes revisited. Annu Rev Biochem 75:295332.

Yeh CJ, Hsi BL, Faulk WP (1981). Propidium iodide as a nuclear marker in immunofluorescence. II. Use with celluIar identification and viability studies. J Immunol Methods 43:269-275.

Zahm JM, Baconnais S, Monier S, et al (2003). Chronology of cellular alterations during 7-ketocholesterol-induced cell death on A7R5 rat smooth muscle cells: analysis by time lapse-video microscopy and conventional fluorescence microscopy. Cytometry A 52:57-69.

Zarrouk A, Riedinger JM, Ahmed SH, et al (2015). Fatty acid profiles in demented patients: identification of hexacosanoic acid (C26:0) as a blood lipid biomarker of dementia. J Alzheimers Dis 44:1349-1359.

Zarrouk A (2013). Implication de l'acide docosanoïque (C22 0) et des acides gras à très longue chaîne (acide tétracosanoïque (C24 0), acide hexacosanoïque (C26 0)) dans la maladie d'Alzheimer: aspects biologiques et cliniques (Doctoral dissertation, Université de Bourgogne).

Zarrouk A, Vejux A, Nury T, et al (2012). Induction of mitochondrial changes associated with oxidative stress on very long chain fatty acids (C22:0, C24:0, or C26:0) treated human neuronal cells (SK-NB-E). Oxid Med Cell Longev 2012:623257. doi: 10.1155/2012/623257. 